\title{
Shoulder isokinetic profile of male handball players of the Brazilian National Team
}

\author{
Marília S. Andrade ${ }^{1}$, Rodrigo L. Vancini' ${ }^{2}$, Claudio A. B. de Lira ${ }^{2}$, \\ Naryana C. Mascarin ${ }^{1}$, Rafael J. F. G. Fachina ${ }^{3,4}$, Antonio C. da Silva ${ }^{1}$
}

\begin{abstract}
Background: Data obtained on an isokinetic dynamometer are useful to characterize muscle status and have been reported in muscle imbalance studies in different types of sport. However, few studies have assessed elite handball players to establish reference values. Objective: The purpose of this study was to compare, for the dominant (D) and non-dominant (ND) side, the isokinetic profile of shoulder rotator muscle strength between male handball players (H) and asymptomatic non-athletes (NA). Method: Isokinetic concentric and eccentric strength tests for D upper limbs were performed by the $\mathrm{H}$ group $(\mathrm{n}=20)$ and the NA group $(\mathrm{n}=12)$. Internal and external rotator muscle peak torque in concentric action was assessed at $60 \% \mathrm{~s}$ and $300 \%$ and in eccentric action at $300 \%$ s. We also calculated conventional balance (the ratio of external rotator peak torque to internal rotator peak torque in concentric action) and functional balance (the ratio of external rotator peak torque in eccentric action to internal rotator peak torque in concentric action). Results: In the H group, dominant limbs were stronger in concentric action for external rotation at 60 and $300 \%$ s. The conventional balance ratio for the D side was significantly lower at 60 and $300 \% \mathrm{~s}$ for $\mathrm{H}$ compared to NA. The functional ratio for the D side was significantly lower at $300 \%$ for $\mathrm{H}$ compared to NA. Conclusions: Compared to asymptomatic non-athletes, handball players presented significant muscular imbalance resulting from daily sports practice, a known risk factor for shoulder injuries.
\end{abstract}

Keywords: physical therapy; muscle strength; isokinetic dynamometer; shoulder joint; athletic injuries; handball.

\section{HOW TO CITE THIS ARTICLE}

Andrade MS, Vancini RL, Lira CAB, Mascarin NC, Fachina RJFG, Silva AC. Shoulder isokinetic profile of male handball players of the Brazilian National Team. Braz J Phys Ther. 2013 Nov-Dec; 17(6):572-578. http://dx.doi.org/10.1590/S1413-35552012005000125

\section{Introduction}

In sporting activities that require repetitive bouts of high-velocity upper limb movement, shoulder injuries and pain are common ${ }^{1-4}$, especially in the limbs involved in high velocity throwing ${ }^{5-7}$. Therefore, a major challenge for health and sports medicine professionals that work with overhead athletes is the development of effective shoulder injury prevention programs. Muscle variables obtained on an isokinetic dynamometer are useful in characterizing muscle status as they provide information about strength, power, endurance, and balance ratio (conventional and functional ratios). In this context, conventional balance ratio (external rotation/internal rotation in concentric action) and functional balance ratio (external rotation in eccentric action/internal rotation in concentric action) have been used by several authors in an attempt to identify muscle strength imbalances that may lead to injury ${ }^{1,6-13}$ and to establish preventive shoulder muscular strengthening programs ${ }^{14,15}$.

Although isokinetic muscle strength measurement has been well studied and reported in muscle imbalance studies in different types of sports activities $^{13,16-19}$, few studies have addressed this issue in handball players. Therefore, the aim of the present investigation is to compare the shoulder functional and conventional balance ratios in male handball players and asymptomatic non-athletes and to establish reference values for the correct interpretation of isokinetic test results in both healthy and injured handball players for performance enhancement, injury prevention, and rehabilitation. We hypothesized that long-term training can cause alterations in the conventional and functional ratios of handball players when compared with non-athletes as a result of the specific muscular requirements of handball.

\footnotetext{
${ }^{1}$ Physiology Department, Universidade Federal de São Paulo (UNIFESP), São Paulo, SP, Brazil

${ }^{2}$ Human and Exercise Physiology Sector, Universidade Federal de Goiás (UFG), Jataí, GO, Brazil

${ }^{3}$ Sports Science Department, Faculty of Physical Education, Universidade Estadual de Campinas (UNICAMP), Campinas, SP, Brazil

${ }^{4}$ Brazilian Basketball Confederation, Rio de Janeiro, RJ, Brazil

Received: 12/19/2012 Revised: 06/28/2013 Accepted: 07/05/2013
} 


\section{Method}

\section{Subjects}

Twenty male handball players and twelve nonathletes, who served as controls, participated in the study. The handball players $(\mathrm{H})$ group was recruited from the Brazilian National Handball Team and the non-athletes (NA) group was composed of students recruited from Universidade Federal de São Paulo (UNIFESP), São Paulo, SP, Brazil. None of the subjects from the NA group were involved in any sports with predominant use of upper limbs, such as volleyball, tennis or swimming. All subjects were informed of the intent and procedures of the study and signed an informed consent form before data collection. The study protocol was approved by the University's Ethics Committee (protocol number: 1053/10, UNIFESP, São Paulo, SP, Brazil). Handball players continued their regular training program and were asked to refrain from strenuous workouts the day before each test with the trainer's consent. The Brazilian National Handball Team is comprised of 4 goalkeepers, 3 circle runners, 5 backs, 4 wingers, and 4 centers. The physical characteristics of the $\mathrm{H}$ group and the NA group were as follows (mean $\pm S D)$ : age: $27.7 \pm 3.7$ yrs; weight: $92.2 \pm 9.7 \mathrm{~kg}$; height: $186.3 \pm 6.7$ $\mathrm{cm}$; and age: $23.4 \pm 2.2 \mathrm{yrs}$ and weight: $66.0 \pm 14.0$ $\mathrm{kg}$; height: $176.2 \pm 7.0 \mathrm{~cm}$, respectively. All subjects were asymptomatic and free from pain and any upper extremity injury at the time of testing as well as over the year before data collection.

\section{Test procedures}

Before isokinetic testing, a 5-min warm-up was performed on an arm-cycle-ergometer (Cybex Inc., Ronkonkoma, NY, USA) at a resistance level of 25 $\mathrm{W}$ followed by light stretching exercises. Following the warm-up, subjects were placed on the isokinetic dynamometer (Cybex - division of Lumex, Cybex 6000, Ronkonkowa, NY, USA) to evaluate concentric and eccentric strength measures for the non-dominant (ND) upper limb, presented only for sample characterization, and the dominant (D) upper limb. Subjects assumed the supine position, and standard stabilization strapping was placed across their chest and hips. The upper extremity was positioned with the shoulder abducted to $90^{\circ}$ and the elbow flexed to $90^{\circ}$, according to manufacturer specification. Strength of internal and external rotators was tested through $120^{\circ}$ of range of motion (between $60^{\circ}$ of internal rotation and $60^{\circ}$ of external rotation). According to Edouard et al. ${ }^{20}$ and Forthomme et al. ${ }^{21}$, who set the maximal external rotation (ER) range of motion at $55^{\circ}$, we chose maximal $60^{\circ}$ for ER action to prevent excessive range of motion of the shoulder joint.

Subjects performed three submaximal trials to familiarize themselves with the range of motion and the accommodating resistance of the dynamometer. The subjects were then tested with a maximum of five repetitions carried out at angular speeds of $60 \%$ and $300 \%$ for concentric action and $300 \%$ for eccentric action. This number of repetitions has demonstrated high reliability for isokinetic testing. The angular testing velocities were chosen according to the criteria of Andrade et al. ${ }^{13}$. All participants were tested on internal rotation first. A 60-s rest period was used between sets for all subjects to prevent fatigue build-up. Consistent verbal commands were given during test. All subjects were tested by one examiner who was trained and experienced in the use of isokinetic testing devices. Before testing, the dynamometer was calibrated according to the manufacturer specifications and was checked prior to testing each subject.

\section{Assessment of conventional and functional ratios}

Because of the critical role of the rotator cuff muscles to shoulder stabilization, the evaluation of shoulder internal rotator and external rotator isokinetic muscle strength is important for rehabilitation and preventive strategies ${ }^{12,13}$. To this end, we established for both groups the conventional ratio (external rotation-internal rotation in concentric action) and the functional ratio (external rotation in eccentric action-internal rotation in concentric action) in order to assess possible muscle strength imbalances which could lead to injuries.

\section{Statistical analysis}

Results are shown as mean $\pm S D$. All variables presented normal distribution according to the Kolmogorov-Smirnov test. A multifactorial repeated measures analysis of variance (ANOVA 2 X 2) was employed to investigate main effects for groups and sides. Statistical analyses were conducted using GraphPad Prism (GraphPad Software, San Diego, CA, USA). The level of significance was set at $P<0.05$. In addition, in the comparisons where significant differences were observed, we calculated Cohen's d and the effect-size correlation values, using the means and standard deviation data of the groups. 


\section{Results}

In order to compare isokinetic peak torque values between groups, we normalized isokinetic peak torque values by the groups' body mass. Table 1 and 2 show the relative values of peak torque found for concentric and eccentric internal and external rotations for the ND and D limbs at 60 and $300 \%$ s, respectively. The relative concentric peak torque values for internal rotation were significantly higher for the $\mathrm{H}$ group on the D side at $60 \% \mathrm{~s}(22.5 \%$, effect size $=-0.92$, and $d=-5.05$ ) and on the ND side (25.3\%, effect size $=-0.94$, and $d=-5.66)$ than those observed in the NA group. In addition, the relative concentric peak torque values for internal rotation were significantly higher for the $\mathrm{H}$ group on the ND side at $300 \% \mathrm{~s}(19.6 \%$, effect size $=-0.90$, and $d=-4.31)$ than those observed in the NA group. In the eccentric action, relative peak torque values for internal rotation were significantly lower for the NA group on the D side at $300 \% \mathrm{~s}(25.0 \%$, effect size $=-0.94$, and $d=-6.0)$ and on the ND side $(26.2 \%$, effect size $=-0.94$, and $d=-5.51$ ) than those observed in the H group.

No differences between sides were found for any of the variables measured or calculated, demonstrating muscular strength and ratio symmetry.

Table 3 shows values for conventional and functional balance ratios for the D and ND upper limbs at 60 and $300 \%$ s. The conventional balance ratio was significantly lower for $\mathrm{H}$ compared to NA at $60 \%$ angular speed on the D side $(29.4 \%$, effect size $=0.91$, and $d=4.47)$ and the ND side $(23.9 \%$, effect size $=0.86$, and $d=3.42$ ) and only significantly lower at $300 \%$ for $\mathrm{H}$ compared to NA on the D side $(23.0 \%$, effect size $=0.99$, and $d=17.0$ ). Moreover, functional ratio was significantly lower $(17.1 \%$, effect size $=0.86$, and $d=3.44$ ) at $300 \%$ s angular speed on the $\mathrm{D}$ side for $\mathrm{H}$ compared to NA.

Table 1. Relative maximal isokinetic concentric joint torque for dominant (D) and non-dominant (ND) upper limbs at 60 and $300 \%$ angular speeds for the non-athlete (NA) group $(n=12)$ and the handball players $(H)$ group $(n=20)$ groups.

ND $\quad$ D

NA H NA H

$60 \% \mathrm{~s}(\mathrm{Nm} / \mathrm{kg})$

$\begin{array}{lcccc}\text { IRCC } & 0.50 \pm 0.03 & 0.67 \pm 0.03^{\dagger} & 0.55 \pm 0.02 & 0.71 \pm 0.04^{\dagger} \\ \text { Range } & 0.36-0.73 & 0.42-1.00 & 0.44-0.80 & 0.47-1.05 \\ \text { ERCC } & 0.46 \pm 0.04 & 0.47 \pm 0.01 & 0.55 \pm 0.04 & 0.51 \pm 0.03 \\ \text { Range } & 0.32-0.86 & 0.37-0.64 & 0.34-1.00 & 0.27-0.82 \\ \text { IRCC } & & & 0.60 \pm 0.03 \\ \text { Range } & 0.45 \pm 0.03 & 0.56 \pm 0.02^{\dagger} & 0.50 \pm 0.03 & 0.41-0.88 \\ \text { ERCC } & 0.34-0.65 & 0.42-0.85 & 0.32-0.73 & 0.44 \pm 0.02 \\ \text { Range } & 0.37 \pm 0.02 * & 0.41 \pm 0.01 & 0.47 \pm 0.02 & 0.27-0.70\end{array}$

Data are expressed as mean \pm SD. IRCC: internal rotation in concentric contraction; ERCC: external rotation in concentric contraction. $\dagger$ Statistically significant difference in relation to NA (ANOVA $2 \times 2, P<0.05$ ). * Statistically significant difference in relation to dominant side (ANOVA $2 \times 2, P<0.05$ ).

Table 2. Relative maximal isokinetic eccentric joint torque for the $\mathrm{D}$ and ND upper limbs at $300 \%$ s angular speed for NA ( $\mathrm{n}=12$ ) and $\mathrm{H}(\mathrm{n}=20)$ groups.

\section{ND}

NA

$300 \% \mathrm{~s}(\mathrm{Nm} / \mathrm{kg})$

$\begin{array}{llccc}\text { IREC } & 0.59 \pm 0.02 & 0.80 \pm 0.05^{\dagger} & 0.63 \pm 0.03 & 0.84 \pm 0.04^{\dagger} \\ \text { Range } & 0.50-0.80 & 0.46-1.46 & 0.40-0.77 & 0.54-1.24 \\ \text { EREC } & 0.60 \pm 0.02 & 0.67 \pm 0.02 & 0.65 \pm 0.03 & 0.65 \pm 0.02 \\ \text { Range } & 0.38-0.77 & 0.52-0.95 & 0.41-0.88 & 0.47-0.86\end{array}$

Data are expressed as mean \pm SD. IREC: internal rotation in eccentric contraction; EREC: external rotation in eccentric contraction. $\uparrow$ Statistically significant difference in relation to NA (ANOVA $2 \times 2, P<0.05$ ). 
Table 3. Peak torque conventional ratio (CR) and functional ratio (FR) for the D and ND upper limbs at 60 and $300^{\circ} / \mathrm{s}$ angular speeds for NA (n=12) and $\mathrm{H}(\mathrm{n}=20)$ groups.

ND

NA

$0.96 \pm 0.09$

$0.6-2.0$

$0.82 \pm 0.05$

$0.5-1.1$

Range

$1.39 \pm 0.10$

$0.9-2.0$
H

$0.73 \pm 0.03^{\dagger}$

$0.5-1.0$

$0.73 \pm 0.02$

$0.6-1.0$

$1.21 \pm 0.05$

$0.9-2.0$
D

NA

H

Data are expressed as mean \pm SD. CR: conventional ratio; FR: functional ratio. $†$ Statistically significant difference in relation to NA (ANOVA $2 \times 2, P<0.05$ ).

\section{Discussion}

There are few studies that evaluate isokinetic shoulder strength in elite athletes, particularly in handball players ${ }^{12,13}$. Therefore, our purpose was to examine isokinetic shoulder measurements in order to establish shoulder strength values and balance ratios (conventional and functional) that could be employed in devising preventive, training, and rehabilitation strategies for shoulder injuries. In general, the $\mathrm{H}$ group was stronger than the NA group for concentric and eccentric strength for internal rotations at 60 and $300 \%$ s angular speeds, even though peak torque values were corrected by body mass. This difference may be a result of daily shoulder training performed by the $\mathrm{H}$ group. In other sports, such as rugby, strength values were also higher in athletes than nonathletes, but when peak torque was normalized to body weight, there were no significant differences ${ }^{22}$.

Previous studies demonstrated that a stronger D $\operatorname{limb}^{19-24}$ is to be expected in asymmetrical sports and that these differences may result from regular sports training ${ }^{12}$. For example, the majority of handball players use one limb to practice most of the powerful throws during the training season. However, elite handball players have been getting bigger over time $^{24}$, requiring very intense resistance training, and this program is composed of a set of symmetrical exercises. It is possible that this type of intense exercise was able to minimize the asymmetrical effect of specific handball training.

Balance ratios for the $\mathrm{H}$ and NA groups, measured at 60 and $300 \%$ s, revealed that the $\mathrm{H}$ group presented significantly lower values of conventional and functional ratios than the NA group at both angular speeds. Lower values for conventional and functional ratios had already been demonstrated for overhead athletes, primarily on the D side ${ }^{1,13,25}$. Noffal ${ }^{1}$ demonstrated a lower ratio in the throwers' dominant limb. The authors have attributed this ratio to a significantly greater concentric internal rotation torque without concomitant eccentric external torque gains. In the same way, other authors also demonstrated a lower shoulder balance ratio for other overhead athletes, such as tennis players ${ }^{26}$, volleyball players ${ }^{25}$, and female handball players ${ }^{13}$. On the other hand, lower ratios for overhead athletes are not a consensus in literature. Codine et al. ${ }^{12}$ demonstrated that balance ratios for overhead athletes were similar to those observed for non-athletes. Similarly, rugby players also presented no difference in balance ratios when compared to non-athletes ${ }^{22}$.

The athletes who participated in the present study showed greater internal and external rotator peak torque values than the NA group, however the difference for the internal rotators was greater than the difference for external rotators strength. As previously mentioned, the lower balance ratios in the $\mathrm{H}$ group are the result of greater strengthening of the internal rotator muscles compared to the external rotator muscles. Therefore, concentric strength exercises for external rotator muscles are recommended for handball athletes to increase conventional and functional ratios and consequently prevent possible injuries associated with muscular imbalance.

While concentric ratios have been helpful in providing an insight into the evaluation of rehabilitation subjects or athlete strength, they may fall short of reflecting muscle function during 
specific sporting activities. Thus, we also compared the functional shoulder ratio at $300 \%$ s. Functional shoulder ratios for the D sides were $1.11 \pm 0.05$ and $1.34 \pm 0.08$ at $300 \%$ s for the $\mathrm{H}$ and NA groups, respectively.

These higher functional ratios for NA compared to $\mathrm{H}$ reflect the greater internal rotation concentric strength compared to the external rotation eccentric strength in the $\mathrm{H}$ group. Previous authors who evaluated functional shoulder strength ratios at $300 \%$ for overhead athletes found similar values. Noffal $^{1}$ obtained values of $1.17 \pm 0.20$ at $300^{\circ}$ s for the D upper limb of throwers. In our previous study with female handball athletes, we found a functional shoulder ratio of $1.54 \pm 0.41$ at $300^{\circ} / \mathrm{s}^{13}$ for the $\mathrm{D}$ limb. Apparently, male handball athletes present lower balance ratios than female athletes. This may be explained by the greater superiority in internal rotator concentric action than the superiority of external rotators in eccentric action in male athletes than in female athletes.

Previous studies that used $90 \%$ s to evaluate muscular functional ratios obtained lower values. Yildiz et al. ${ }^{19}$ found a ratio of $1.03 \pm 0.80$ for the D upper limb of overhead athletes. The functional ratios of baseball players, also assessed at $90 \%$, presented a similar value of $1.03 \pm 0.80$ for the $\mathrm{D}$ side $^{27}$. Lower functional balance ratios assessed at $90 \%$ s may be explained by the fact that concentric maximal peak torque decreases as the angular speed of action increases, but eccentric action remains the same or increases, consequently the ratio of external rotator eccentric action to internal rotator eccentric action increases as angular testing speed increases.

Functional ratios above 1.0 indicate that the eccentric strength of the external rotator muscles was greater than the strength of the concentric internal rotator muscles. This greater strength may be necessary to decelerate the rapid throwing movement of the upper limb ${ }^{13,28-30}$. We believe that these reference values for the $\mathrm{H}$ and NA groups may be useful in devising physical training or rehabilitation, as previous authors have demonstrated the effectiveness of preventive strengthening programs ${ }^{14}$.

Additionally, there are inherent difficulties in study comparisons related to the shoulder rotator muscles, due to differences in test equipment, upper limb position during the isokinetic strength test, and the angular speed at which the isokinetic strength test is performed. In the literature, there are different test positions that can be used for isokinetic strength testing in the shoulder joint ${ }^{13,18,31-33}$. The present study chose to test in the supine position with the shoulder at $90^{\circ}$ abduction and the elbow flexed to $90^{\circ}$ as previously described ${ }^{13,33,34}$ to better compare our results. The position selected for this study closely mimicked the functional throw of the shoulder in overhead activities such as handball, better at $20^{\circ}$ or $30^{\circ}$ of shoulder abduction in the scapular plane.

In conclusion, strength data obtained by the present study revealed that the $\mathrm{D}$ shoulder joint in handball players is stronger than in non-athletes, even though peak torque values were corrected by body mass. But given that the internal rotator muscles were much stronger than the external rotators, there was muscular imbalance in the $\mathrm{H}$ group, possibly due to the type of sports training performed daily by these athletes. Therefore, strength exercises for the external rotator muscles are recommended to improve balance ratios and consequently minimize the risk factor for injuries associated with muscular imbalance.

\section{Acknowledgments}

The athletes and non-athletes who volunteered their time to participate in this study. We are also grateful to the directors of the Brazilian Handball Confederation (Confederação Brasileira de Handebol - $\mathrm{CBH}$ ) and the Olympic Training and Research Center (Centro Olímpico de Treinamento e Pesquisa - COTP, São Paulo, Brazil).

This study was funded by Studies and Projects Finance Organization (Financiadora de Estudos e Projetos - FINEP).

\section{References}

1. Noffal GJ. Isokinetic eccentric-to-concentric strength ratios of the shoulder rotator muscles in throwers and nonthrowers. Am J Sports Med. 2003;31(4):537-41. PMid:12860541.

2. Myklebust G, Hasslan L, Bahr R, Steffen K. High prevalence of shoulder pain among elite Norwegian female handball players. Scand J Med Sci Sports. 2013 Jun;23(3):288-94. http://dx.doi.org/10.1111/j.1600-0838.2011.01398.x

3. Mohseni-Bandpei MA, Keshavarz R, Minoonejhad H, Mohsenifar H, Shakeri H. Shoulder pain in Iranian elite athletes: the prevalence and risk factors. J Manipulative Physiol Ther. 2012;35(7):541-8. PMid:22921331. http:// dx.doi.org/10.1016/j.jmpt.2012.07.011

4. Jan J, Benkalfate T, Rochcongar P. The impact of recurrent dislocation on shoulder rotator muscle balance (a prospective study of 102 male patients). Ann Phys Rehabil Med. 2012;55(6):404-14. PMid:22835451. http://dx.doi. org/10.1016/j.rehab.2012.05.004

5. Hutchinson MR, Laprade RF, Burnett QM 2nd, Moss $\mathrm{R}$, Terpstra J. Injury surveillance at the USTA Boys' Tennis Championships: a 6-yr study. Med Sci Sports Exerc. 1995;27(6):826-30. PMid:7658943. http://dx.doi. org/10.1249/00005768-199506000-00006 
6. McConnell J, Donnelly C, Hamner S, Dunne J, Besier T. Effect of shoulder taping on maximum shoulder external and internal rotation range in uninjured and previously injured overhead athletes during a seated throw. J Orthop Res. 2011;29(9):1406-11. PMid:21437968. http://dx.doi. org/10.1002/jor.21399

7. McConnell J, Donnelly C, Hamner S, Dunne J, Besier T. Passive and dynamic shoulder rotation range in uninjured and previously injured overhead throwing athletes and the effect of shoulder taping. PM R. 2012;4(2):1116. PMid:22373460. http://dx.doi.org/10.1016/j. pmrj.2011.11.010

8. Alderink GJ, Kuck DJ. 1sokinetic Shoulder Strength of High School and College-Aged Pitchers*. J Orthop Sports Phys Ther. 1986;7(4):163-72. PMid:18802268.

9. Brown LP, Niehues SL, Harrah A, Yavorsky P, Hirshman HP. Upper extremity range of motion and isokinetic strength of the internal and external shoulder rotators in major league baseball players. Am J Sports Med. 1988;16(6):577-85. PMid:3239614. http://dx.doi. org/10.1177/036354658801600604

10. Ellenbecker TS. A total arm strength isokinetic profile of highly skilled tennis players. Isokinetics Exerc Sci. 1991;1:9-21.

11. Ellenbecker TS, Mattalino AJ. Concentric isokinetic shoulder internal and external rotation strength in professional baseball pitchers. J Orthop Sports Phys Ther. 1997;25(5):323-8. http://dx.doi.org/10.2519/ jospt.1997.25.5.323

12. Codine P, Bernard PL, Pocholle M, Benaim C, Brun V. Influence of sports discipline on shoulder rotator cuff balance. Med Sci Sports Exerc. 1997;29(11):1400-5. PMid:9372473. http://dx.doi. org/10.1097/00005768-199711000-00002

13. Andrade Mdos S, Fleury AM, De Lira CA, Dubas JP, Da Silva AC. Profile of isokinetic eccentric-toconcentric strength ratios of shoulder rotator muscles in elite female team handball players. J Sports Sci. 2010;28(7):743-9. PMid:20496224. http://dx.doi. org/10.1080/02640411003645687

14. Camargo PR, Avila MA, Alburquerque-Sendín F, Asso NA, Hashimoto LH, Salvini TF. Eccentric training for shoulder abductors improves pain, function and isokinetic performance in subjects with shoulder impingement syndrome: a case series. Rev Bras Fisioter. 2012;16(1):74-83. PMid:22441232. http://dx.doi. org/10.1590/S1413-35552012000100013

15. Michener LA, Walsworth MK, Burnet EN. Effectiveness of rehabilitation for patients with subacromial impingement syndrome: a systematic review. J Hand Ther. 2004;17(2):152-64. PMid:15162102. http://dx.doi. org/10.1197/j.jht.2004.02.004

16. Bak K, Magnusson SP. Shoulder strength and range of motion in symptomatic and pain-free elite swimmers. Am J Sports Med. 1997;25(4):454-9. http://dx.doi. org/10.1177/036354659702500407

17. Mikesky AE, Edwards JE, Wigglesworth JK, Kunkel S. Eccentric and concentric strength of the shoulder and arm musculature in collegiate baseball pitchers. Am J Sports
Med. 1995;23(5):638-42. PMid:8526283. http://dx.doi. org/10.1177/036354659502300520

18. McMaster WC, Long SC, Caiozzo VJ. Shoulder torque changes in the swimming athlete. Am J Sports Med. 1992;20(3):323-7. PMid:1636864. http://dx.doi. org/10.1177/036354659202000315

19. Yildiz Y, Aydin T, Sekir U, Kiralp MZ, Hazneci B, Kalyon TA. Shoulder terminal range eccentric antagonist/concentric agonist strength ratios in overhead athletes. Scand J Med Sci Sports. 2006;16(3):174-80. PMid:16643195. http:// dx.doi.org/10.1111/j.1600-0838.2005.00471.x

20. Edouard P, Degache F, Oullion R, Plessis JY, GleizesCervera S, Calmels P. Shoulder Strength Imbalances as Injury Risk in Handball. Int J Sports Med. 2013 Jul;34(7):654-60. PMid:23444085. http://dx.doi. org/10.1055/s-0032-1312587

21. Forthomme B, Dvir Z, Crielaard JM, Croisier JL. Isokinetic assessment of the shoulder rotators: a study of optimal test position. Clin Physiol Funct Imaging. 2011;31(3):227-32. PMid:21470363. http://dx.doi. org/10.1111/j.1475-097X.2010.01005.X

22. Edouard P, Frize N, Calmels P, Samozino P, Garet M, Degache F. Influence of rugby practice on shoulder internal and external rotators strength. Int J Sports Med. 2009;30(12):863-7. PMid:19908173. http://dx.doi. org/10.1055/s-0029-1237391

23. Silva RT, Gracitelli GC, Saccol MF, Laurino CF, Silva AC, Braga-Silva JL. Shoulder strength profile in elite junior tennis players: horizontal adduction and abduction isokinetic evaluation. Br J Sports Med. 2006;40(6):513-7; discussion 517. PMid:16488900 PMCid:PMC2465104. http://dx.doi.org/10.1136/bjsm.2005.023408

24. Norton K, Olds T. Morphological evolution of athletes over the 20th century: causes and consequences. Sports Med. 2001;31(11):763-83. http://dx.doi. org/10.2165/00007256-200131110-00001

25. Wang HK, MacFarlane A, Cochrane T. Isokinetic performance and shoulder mobility in elite volleyball athletes from the United Kingdom. Br J Sports Med. 2000;34(1):39-43. PMid:10690449 PMCid:PMC1724158. http://dx.doi.org/10.1136/bjsm.34.1.39

26. Gozlan G, Bensoussan L, Coudreuse JM, Fondarai J, Gremeaux V, Viton JM, et al. Isokinetic dynamometer measurement of shoulder rotational strength in healthy elite athletes (swimming, volley-ball, tennis): comparison between dominant and nondominant shoulder. Ann Readapt Med Phys. 2006;49(1):8-15. PMid:16122829. http://dx.doi.org/10.1016/j.annrmp.2005.07.001

27. Scoville CR, Arciero RA, Taylor DC, Stoneman PD. End range eccentric antagonist/concentric agonist strength ratios: a new perspective in shoulder strength assessment. J Orthop Sports Phys Ther. 1997;25(3):2037. PMid:9048326. http://dx.doi.org/10.2519/ jospt.1997.25.3.203

28. Feltner M, Dapena J. Dynamics of shoulder and elbow joints of the throwing arm during a baseball pitch. Int J Sport Biomech. 1986;2(4):235-259.

29. Dillman CJ, Fleisig GS, Andrews JR. Biomechanics of pitching with emphasis upon shoulder kinematics. J 
Orthop Sports PhysTher. 1993;18(2):402-8. http://dx.doi. org/10.2519/jospt.1993.18.2.402

30. Escamilla RF, Fleisig GS, Zheng N, Barrentine $\mathrm{SW}$, Andrews JR. Kinematic comparisons of 1996 Olympic baseball pitchers. J Sports Sci. 2001;19(9):665-76. PMid:11522142. http://dx.doi. org/10.1080/02640410152475793

31. Otis JC, Warren RF, Backus SI, Santner TJ, Mabrey JD. Torque production in the shoulder of the normal young adult male. The interaction of function, dominance, joint angle, and angular velocity. Am J Sports Med. 1990;18(2):119-23. PMid:2343976. http://dx.doi. org/10.1177/036354659001800201

32. Leroux JL, Codine P, Thomas E, Pocholle M, Mailhe D, Blotman F. Isokinetic evaluation of rotational strength in normal shoulders and shoulders with impingement syndrome. Clin Orthop Relat Res. 1994;(304):108-15. PMid:8020202.
33. Wilk KE, Arrigo CA. Isokinetic exercise and testing for shoulder. In: Andrews JR, Wilk KE, edittors. The athlete's shoulders. New York: Churchill Livingstone; 1994. p 523-542.

34. Aydin T, Yildiz Y, Yildiz C, Kalyon TA. The stretchshortening cycle of the internal rotators muscle group measured by isokinetic dynamometry. J Sports Med Phys Fitness. 2001;41(3):371-9. PMid:11533569.

\section{Correspondence}

Marília dos Santos Andrade

Universidade Federal de São Paulo

Departamento de Fisiologia

Rua Botucatu, 862, 5o. andar,

Edifício de Ciências Biomédicas, Vila Clementino, CEP: 04023-062, São Paulo, SP, Brazil

e-mail: marilia1707@gmail.com 